\title{
Akdeniz Ůzerine Tezler: Bir Bibliyografya Denemesi
}

\section{Gökhan Korkmaz**}

Bu bibliyografya, Yükseköğretim Kurulu Başkanlığı Ulusal Tez Merkezi veri tabanında "Akdeniz" ve "Uluslararası İlişkiler" anahtar sözcükleri ile yapılan bir taramayla derlenmiştir. 1994 ile 2017 arasında kabul edilen tezleri kapsamaktadır. Amaç, Türkiye'de hazırlanan Uluslararası İlişkiler tezlerinin Akdeniz'i nasıl işledikleri ve hangi konulara dikkat çektiklerini anlamaya çalışmaktır.

Akdeniz gibi geniş bir coğrafi bölgenin Uluslararası İlişkiler'in çok yönlü bakış açısıyla birleştiğinde pek çok kesişim kümesi olduğu açıktır. Çalışmanın, bu kümelerin tamamına değinmek ve hepsini incelemek iddiası taşımadan, olabildiğince geniş tutulması hedeflenmiştir.

Tezler incelendiğinde, konuyu ele alışları bakımından bazı ortaklıklar tespit edilmiş ve bu yönde bir sınırlandırmaya gidilmiştir. Bu ortaklıkları, Avrupa-Akdeniz ilişkisi, güvenlik, ekonomi, doğal kaynaklar, çevre, Kıbrıs ve göç başlıkları altında sınıflandırmak mümkün görülmektedir.

\section{Avrupa-Akdeniz İlişkisi}

Avrupa ülkeleri ve Avrupa Birliği kurumlarının Akdeniz bölgesi ile girdiği çok yönlü ilişkinin çapı geniştir. Tezler de bu genişlikten ötürü çeşitli bakış açılarına sahiptir. Arap Baharı ve sonrasında Avrupa Birliği'nin Akdeniz politikalarının nasıl şekillenebileceği incelenmiştir (Aksoy 2015). Ortadoğu ile kurulan ilişkilerin istikrar içinde olabilmesi için Avrupa Birliği açısından demokrasi politikalarının bölgedeki anlamı araştırılmış ve konunun ekonomik boyutuna dikkat çekilmiştir (Bıyıklı 2006; Bulat 2013; Demircan 2012). Akdeniz'in kuzeyi ve güneyi arasındaki farklılıklar vurgulanarak, bu iki bölgenin nasıl ilişkiler kurduğu, iktisadi ilişkiler üzerinden değerlendirilmiştir (Doğanyılmaz 2012). Avrupa-Akdeniz ortaklığı amacıyla atılan adımların ve bu adımların yenilenmiş halinin Türkiye açısından önemi incelenmiş, bu ortaklık kapsamında Avrupa Birliği üyesi olmayan ülkeler ve Türkiye'nin iktisadi ilişkisi araştırılmıştır (Eylemer 2003; Neşe 1996; Kaleci 2003). Avrupa-Akdeniz ortaklığının güvenlik ayağında ise Avrupa'nın rolü ve güvenlik politikaları incelenmiştir (Göksu 2007). Bazı tezlerin konusu, Fransa ve İngiltere'nin Doğu Akdeniz'deki çok yönlü mücadelesi, Fransa'nın Akdeniz'e ilişkin dış politikası ve faaliyetleri ve yine Fransa'nın Akdeniz için birlik politikası olmuştur (Görgen 2013; Kolutek 2011; Mammadov 2009). Avrupa Birliği'nin Akdeniz politikalarının zamanla değişim gösterdiği ve giderek azalan bir işbirliğine dönüştüğü yapılan ortaklık anlaşmaları üzerinden değerlendirilmiş, yürütülen özel projelerin tamamlayıcı ya da rakip olma durumları tartışılmış, özel olarak kültürel diyalog üzerindeki etkileri araştırılmış, Akdeniz Eylem Planı́nın Türk-Yunan ilişkisine etkisi incelenmiş ve yine bu anlaşmaların genişlemelere etkisi araştırılmıştır (Kaleli 2011; Noi 2009; Savc1 2006; Kurt 2002; Oktay 2007). Avrupa Birliği politikalarının değişime uğramasının Türkiye için ne anlama geldiği ve üyeliğe etkisi tezlerde farklı şekillerde değerlendirilmiştir (Kasapoğlu 2000; Sicim 2007). Bazı tezler-

\footnotetext{
* Efthimios Maheras, Yusuf Can Gökmen, Erinç Kuzu ile yardım ve rehberliği ile yol gösteren Ayşegül Sabuktay'a teşekkürlerimi sunarım.

** Ege Üniversitesi, Uluslararası İlişkiler Bölümü
} 
de, Avrupa Birliği ve Akdeniz politikası genel olarak değerlendirilmiştir (Özen 2011; Yiğit 2008). Bu tezlerin dışında Avrupa Birliği politikalarının birliğe üye devletlere etkilerini inceleyen tezler de bulunmaktadır. Bölgesel politikaların İspanya ve Yunanistan üzerindeki etkisi, Euro-Med politikasının İtalya üzerindeki güvenlik temelli etkisi üzerine yapılan çalışmalar, sunulan tezler arasındadır (Yanık 2011; Yavaş 2010). Hemen her konu, coğrafyanın büyük bir kısmını kapsayan ve etkili aktörler olan Avrupa devletleri ile ilişkili olacağından, konu özelindeki sınırlandırmaya dikkat edilmeye çalışılmış ve Avrupa devletlerinin diğer konular ile ilişkisi için tezlerin tamamı burada değerlendirilmemiştir.

\section{Güvenlik}

Akdeniz'e ilişkin Uluslararası İlişkiler tezlerinde bir diğer önemli başlık güvenliktir. Uluslararası deniz sorunları kapsamında Doğu Akdeniz'in durumu, bu sorunların hukuksal ve küresel perspektiften güvenlik boyutları araştırılmıştır (Kaya 2007; Özbilenler 2015; Kesgin 2015). Soğuk Savaş sonrası olumlu güvenlik atmosferinin güneyden gelecek tehditlerle bozulacağ endişesi ve bu durum karşısında Avrupa Birliği ve NATO'nun rolleri tartışılmış, NATO'nun güvenlik anlayışı incelenmiştir (Denizer 2001; Bilgici 2004). 1995 Barselona sürecinin güvenlik üzerindeki etkisi Akdeniz'de terörizm bağlamında değerlendirilmiştir (Dinç 1999). İsrail, Cezayir, Yunanistan, Libya, Türkiye ve bölgede etkili bir aktör olan ABD ile Avrupa Birliği'nin Akdeniz güvenliği üzerindeki etkileri farklı boyutları ile tezlere konu olmuştur (Özdemir 2002; Çelenk 2003; Bozdemir 2015; Uçak 2008). Akdeniz güvenliğine yetki alanları açısından yaklaşan ve tartışan tezlerin yanında daha genel bir perspektiften kaleme alınmış, çok aktörlü güvenlik değerlendirmeleri de bulunmaktadır (Şeker 2014; Kafdağl1 2013; Şanlı 2012). Bunların yanı sıra Akdeniz güvenlik projeleri ve Türkiye açısından sonuçlarına ilişkin bir tez ile Avrupa Birliği komşuluk politikasına, Akdeniz güvenliğine hegemonya kavramıla yaklaşan bir başka tez de dikkat çekmektedir (Uysal 2001; Kocabaş 2016).

\section{Ekonomi}

Akdeniz bölgesi hakkında özel olarak çalışılan Uluslararası İlişkiler tezlerinde işlenen bir diğer önemli genel başlık ekonomi olarak karşımıza çıkmaktadır. Doğu Akdeniz münhasır ekonomik bölgeler uyuşmazlığı, askeri faaliyetler ve hukuk üzerinden değerlendirilmiştir (Alptekin 2016). Avrupa Akdeniz İşbirliği bölgesinde ekonomik bağımlılığın Güney Akdeniz ülkelerine etkisi tartışılmıştır (Aydın 2015). Sermaye hareketleri, Avrupa Birliği'ne üye olmayan ülkeler üzerinden incelenmiştir (Bilgili 2003). Türkiye konusundaki tezlerden birinde, Türkiye gümrük birliği sürecinde Avrupa Birliği üyesi olmayan ülkelerle ticari ilişkisi çerçevesinde incelenmiş; bir diğerinde, Avrupa Birliği'nden Akdeniz ülkelerine ve Türkiye'ye yapılan mali yardımların analizi yapılmıştır (Kaleci 2003; Yücel 2009).

\section{Doğal Kaynaklar}

Ekonomi başlığıyla ilişkili olarak doğal kaynakların durumunu konu alan tezler de mevcuttur. Doğalgazın Türkiye-Yunanistan ve Türkiye-İsrail ilişkisine etkisi tartışılmış, Kıbrıs sorunuyla bağlantısı sorgulanmıştır (Georgopoulou 2015; Başar 2015; Algun 2015). Deniz hukuku ve münhasır ekonomik bölge uyuşmazlığı üzerinden petrol, doğalgaz ve potansiyel enerji kaynakları ele alınmıştır (Kaya 2014; Kürbüz 2016). Akdeniz havzası su potansiyeli ve hidropolitiği ile ilgilenen tezler de mevcuttur (Yıldız 2000). 
Çevre

Çevre başlığı altında toplanabilecek tezlerin büyük çoğunluğu, Akdeniz için toplu olarak yapılan projelerin çevre boyutunu analiz etmeye çalışmıştır. 1975 Akdeniz Eylem Planı ve ek protokolleri çevre politikaları üzerinden incelenmiş, bazı durumlarda özel dosya olarak Kıbrıs'a yer verilmiştir (Çokişler 2015; Koçer 1998; Pulat 2007; Talu 1995; Ziyal 1994; Köprülü 2006). Akdeniz Eylem Planı bağlamında özel koruma alanlarını konu edinen bir çalışma da mevcuttur (Zorlu 2011).

\section{Kıbris ve Göç}

Akdeniz'de göç ve Kıbrıs konularını inceleyen pek çok tez bulunmaktadır. AB'nin Akdeniz politikası ve Kıbrıs bazı durumlarda beraber araştırılmıştır (Altunay 1995). Balkanlar ve Ortadoğu örnekleri 1şığında Kıbrıs'ın siyasi geleceği incelenmiştir (Günal 2005). Kıbrıs üzerinden, kimlik ve doğal kaynakları beraber incelemeyi amaçlamış tezler de bulunmaktadır (İşlek 2016). Kıbrıs'ın stratejik önemi de konu olmuştur (Başak 2006). Göç konusunda da incelemeler yapılmıştır. Bu başlık altındaki tezler arasında Gana, Suriye, İsrail, Lübnan ve Avrupa konularında özel çalışma yapmış olanlar dikkat çekmektedir (Abdallah 2012; Bilgili 2006).

Uluslararası İlişkiler ve Akdeniz çalışmalarının kesişim kümeleri oldukça çeşitlidir ve daha fazla çeşitlenmeye de elverişlidir. Bu bibliyografya çalışmasının fikir düzeyinde dahi olsa diğer çalışmalara yardımcı olmasını dilerim.

Ayşe Aslıhan Çelenk, "Military and Democracy in Turkey and Algeria: The Success or Failure of EU's Mediterranean Policy" (Yüksek Lisans Tezi, Ihsan Doğramacı Bilkent Üniversitesi, Ankara, 2003).

Aşkın Berk Özdemir, "The Turkish-Israeli Strategic Co-operation and Mediterranean Security" (Yüksek Lisans Tezi, Marmara Üniversitesi, İstanbul, 2002). 
Abdul Jalil Abdallah, "From Ghana to Fortress Europe: The Rights and Wrongs of Crossing Mediterranean” (Yüksek Lisans Tezi, Zirve Üniversitesi, Gaziantep, 2012).

Aylin Ünver Noi, “Euro-Mediterranean Partnership Compared to Broader Middle East and North Africa Initiative: Competing or Complementary Projects?" (Doktora Tezi, Marmara Üniversitesi, İstanbul, 2009).

Ahmet Bıyıklı, “Avrupa Birliği'nin Akdeniz ve Ortadoğu Ülkelerine Yönelik Demokrasi ve İstikrar Politikaları" (Yüksek Lisans Tezi, Selçuk Üniversitesi, Konya, 2006).

Aliye Akın, “Akdeniz Ülkelerindeki Turizm Potansiyellerinin ve Gelirlerinin Makroekonomi Üzerindeki Etkileri” (Yüksek Lisans Tezi, Kahramanmaraş Sütçü İmam Üniversitesi, Kahramanmaraş, 2017).

Aslı Köprülü, "Europeanization of the Environmental Policy in the Mediterranean Region: Case Study of Cyprus" (Yüksek Lisans Tezi, Marmara Üniversitesi, İstanbul, 2006).

Aydan Özen, “Avrupa Birliği’nin Akdeniz Politikası” (Yüksek Lisans Tezi, Gazi Üniversitesi, Ankara, 2011).

Burak Şakir Şeker, “Akdeniz'de Yetki Alanları ve Akdeniz Güvenliği” (Doktora Tezi, Kocaeli Üniversitesi, Kocaeli, 2014).

Banu Koçer, "The Environmental Policy within the Framework of the Euro-Mediterranean Partnership" (Yüksek Lisans Tezi, Marmara Üniversitesi, İstanbul, 1998).

Batuhan Başar, “Doğu Akdeniz Doğal Gazının Türkiye İsrail Etkileşimi Bağlamında Oyun Teorisi ile Analizi" (Yüksek Lisans Tezi, Harp Akademileri Komutanlığı Stratejik Araştırmalar Enstitüsü, İstanbul, 2015).

Cemhan Kocabaş, “Hegemonya ile Sınır Güvenliği: AB Komşuluk Politikasının Akdeniz Havzası Uygulamalarının Eleştirel Teorinin Hegemonya Kavramı Tarafından Değerlendirilmesi" (Doktora Tezi, Karadeniz Teknik Üniversitesi, Trabzon, 2016).

Ceren Uysal, "Mediterranean Security Projects (With Some Implications on Turkey)" (Yüksek Lisans Tezi, Marmara Üniversitesi, İstanbul, 2001).

Dilek Elvan Çokişler, "The Role of Compliance in Effectiveness of International Environmental Regimes: A Case of Mediterranean Sea Regimes" (Doktora Tezi, Dokuz Eylül Üniversitesi, İzmir, 2015).

Devrim Kasapoğlu, “Avrupa Birliği'nin Akdeniz Politikası ve Türkiye” (Yüksek Lisans Tezi, Ankara Üniversitesi, Ankara, 2000).

Didem Doğanyılmaz, “Avrupa Birliği ile Akdeniz Ülkeleri Arasındaki Iktisadi ilişskiler” (Yüksek Lisans Tezi, İstanbul Kültür Üniversitesi, İstanbul, 2012).

Dilek Yiğit, “Avrupa Birliği'nin Akdeniz Politikasının Gelişimi” (Doktora Tezi, Ankara Üniversitesi, Ankara, 2008).

Dursun Yıldız, “Akdeniz Havzasının Su Potansiyeli ve Hidropolitiği” (Yüksek Lisans Tezi, Hacettepe Üniversitesi, Ankara, 2000).

Esra Tuğaç Demircan, "Akdeniz İçin Birlik Projesi ve Ortadoğu” (Yüksek Lisans Tezi, Atılım Üniversitesi, Ankara, 2012).

Ecem Algun, "The Potential Impact of Eastern Mediterranean Natural Gas Development on the Cyprus Conflict” (Yüksek Lisans Tezi, İzmir Ekonomi Üniversitesi, İzmir, 2015).

Eda Zorlu, "Specially Protected Areas Within the Context of the Mediterranean Environmental Programme" (Yüksek Lisans Tezi, Orta Doğu Teknik Üniversitesi, Ankara, 2011).

Erhan Bozdemir, "Libya Odaklı Orta Akdeniz Deniz Yetki Alanları Ihtilaflarının Çözümünün İncelenmesi” (Yüksek Lisans Tezi, İstanbul Teknik Üniversitesi, İstanbul, 2015). 
Erkan Yücel, “Akdeniz Ülkeleri ve Türkiye'ye Yönelik Avrupa Birliği Mali Yardımlarının Analizi" (Yüksek Lisans Tezi, Ankara Üniversitesi, Ankara, 2009).

Gökçen Yavaş, "Euro-Mediterranean Security and Italy: From the Regional Security Complex Theory Perspective" (Doktora Tezi, Marmara Üniversitesi, İstanbul, 2010).

İslam Safa Kaya, "Uluslararası Deniz Hukuku Çerçevesinde Doğu Akdeniz'deki Petrol ve Doğalgaz Kaynakları ile Türkiye'nin Hukuki Konumu” (Doktora Tezi, Kırıkkale Üniversitesi, Kırıkkale, 2014).

ibrahim Özbilenler, "Uluslararası Deniz Hukuku Bağlamında Doğu Akdeniz Münhasır Ekonomik Bölge Sorunu" (Yüksek Lisans Tezi, Marmara Üniversitesi, İstanbul, 2015).

irem Bulat, "The European Union's Democracy Promotion Strategy in Mediterranean Region" (Yüksek Lisans Tezi, Sabancı Üniversitesi, İstanbul, 2013).

İsmail Görgen, “Doğu Akdeniz'de İngiliz Fransız Mücadelesi” (Yüksek Lisans Tezi, Mustafa Kemal Üniversitesi, Hatay, 2013).

Kezban Altunay, "The Mediterranean Policy of the European Union and Cyprus" (Yüksek Lisans Tezi, Marmara Üniversitesi, i̇stanbul, 1995).

Khalid Mammadov, "Fransız Dış Politikasında Akdeniz ve Akdeniz Için Birlik Projesi" (Yüksek Lisans Tezi, Ankara Üniversitesi, Ankara, 2009).

Levent Kürbüz, “Doğu Akdeniz Münhasır Ekonomik Bölge Uyuşmazlığı ve Doğu Akdeniz'deki Potansiyel Enerji Kaynaklarının Analizi" (Yüksek Lisans Tezi, Kara Harp Okulu Komutanlığı Savunma Bilimleri Enstitüsü, Ankara, 2016).

Mehmet Mert Kaleci, “Avrupa-Akdeniz Ortaklığı ve Gümrük Birliği Sürecinde Türkiye'nin AB Üyesi Olmayan Akdeniz Ülkeleri ile Dış Ticaret ilişkileri" (Yüksek Lisans Tezi, İstanbul Üniversitesi, İstanbul, 2003).

Mahmut Alptekin, “Doğu Akdeniz'de Münhasır Ekonomik Bölge Sınırlandırması Uyuşmazlığı Kapsamında Yürütülen Askeri Faaliyetlerin Hukuki Statüsü" (Yüksek Lisans Tezi, Dokuz Eylül Üniversitesi, i̇zmir, 2016).

Marina Georgopoulou, "The Greek Turkish Relations in Terms of Natural Gas Networks in Southern Europe and Eastern Mediterranean" (Yüksek Lisans Tezi, İstanbul Bilgi Üniversitesi, îstanbul, 2015).

Mert Pelindağ, "Ortaçağ Türk Denizciliği ve Ege-Akdeniz Adalarının Fethi” (Yüksek Lisans Tezi, Celal Bayar Üniversitesi, Manisa, 2000).

Metin Bilgici, "Mediterranean Security Role of NATO" (Yüksek Lisans Tezi, Yeditepe Üniversitesi, İstanbul, 2004).

Mikail Kolutek, "Fransa'nın Doğu Akdeniz Havzasındaki Misyonerlik Faaliyetleri” (Yüksek Lisans Tezi, Mustafa Kemal Üniversitesi, Hatay, 2011).

Murat Sicim, “Avrupa Birliği'nin Akdeniz Politikası ve Türkiye” (Yüksek Lisans Tezi, Ankara Üniversitesi, Ankara, 2007).

Münür Bilgili, “Doğu Akdeniz Kıyısında (Suriye, Lübnan, İsrail) Yaşanan Göçler ve Devlet Oluşum Süreçlerine Etkileri" (Yüksek Lisans Tezi, Marmara Üniversitesi, İstanbul, 2006).

Neşe Ülker, "Yenileştirilmiş Akdeniz Politikasında Türkiye'nin Yeri” (Yüksek Lisans Tezi, Anadolu Üniversitesi, Eskişehir, 1996).

Nur Ziyal, "The Marine Pollution Issue in International Relations: The Mediterranean Action Plan" (Yüksek Lisans Tezi, Orta Doğu Teknik Üniversitesi, Ankara, 1994).

Olcay Denizer, "Security Challenges and Institution Initiatives in the Mediterranean" (Yüksek Lisans Tezi, ihsan Doğramacı Bilkent Üniversitesi, Ankara, 2001). 
Onuralp Aydın, “Avrupa Akdeniz İşbirliği Bölgesinde Ekonomik Bağımlılığın Güney Akdeniz Ülkelerine Etkileri” (Yüksek Lisans Tezi, TOBB Ekonomi ve Teknoloji Üniversitesi, Ankara, 2015).

Özgür Bilgili, “Avrupa Birliği'ne Üye Olmayan Akdeniz Ülkelerinin Sermaye Hareketleri” (Yüksek Lisans Tezi, Yıldız Teknik Üniversitesi, İstanbul, 2003).

Resül Orçun Pulat, “Revised Mediterranean Action Plan (Map) For a Sustainable Mediterranean Environment” (Yüksek Lisans Tezi, Marmara Üniversitesi, İstanbul, 2007).

Saime Şanlı, "Uluslararası ilişkiler Bağlamında Güvenlik ve Strateji Boyutunda Akdeniz" (Yüksek Lisans Tezi, Atılım Üniversitesi, Ankara, 2012).

Seda Göksu, “Avrupa-Akdeniz Ortaklığının Güvenlik Boyutunda AB'nin Uluslararası Aktörlüğünün Değerlendirilmesi” (Yüksek Lisans Tezi, Ankara Üniversitesi, Ankara, 2007).

Sedef Eylemer, “Avrupa-Akdeniz Ortaklığı ve Türkiye Açısından Değerlendirilmesi” (Yüksek Lisans Tezi, Dokuz Eylül Üniversitesi, İzmir, 2003).

Serdar Kesgin, “Küresel ve Bölgesel Perspektiften Doğu Akdeniz Güvenliği” (Doktora Tezi, Karadeniz Teknik Üniversitesi, Trabzon, 2015).

Serpil İşlek, "The Reflections of Identity in Cyprus: Claims and Perspectives on Eastern Mediterranean Hydrocarbons" (Yüksek Lisans Tezi, Orta Doğu Teknik Üniversitesi Kuzey Kıbrıs Kampüsü, Güzelyurt, 2016).

Sibel Oktay, "The Impact of the Eastern Enlargement of the European Union on the Euro-Mediterranean Partnership: An Analysis of Member State Preferations" (Yüksek Lisans Tezi, Sabancı Üniversitesi, İstanbul, 2007).

Sibel Yanık, "Regional Policy of the European Union and A Case of Two Mediterranean Countries (Spain, Greece)" (Yüksek Lisans Tezi, Bahçeşehir Üniversitesi, İstanbul, 2011).

Siret Dinç, "An Analysis of the Security Aspect of Euro-Mediterranean Relations in the Barcelona Process" (Yüksek Lisans Tezi, Orta Doğu Teknik Üniversitesi, Ankara, 1999).

Süleyman Aksoy, “Arap Baharı Sonrasında Avrupa Birliği'nin Akdeniz Politikası” (Yüksek Lisans Tezi, İstanbul Üniversitesi, İstanbul, 2015).

Şenay Kaya, "Uluslararası Deniz Sorunu Kapsamında Doğu Akdeniz Sorunları" (Yüksek Lisans Tezi, Ankara Üniversitesi, Ankara, 2007).

Tuğçe Kafdağlı, "Kriz Yönetimi Açısından Doğu Akdeniz Yetki Alanları Uyuşmazlığı” (Yüksek Lisans Tezi, Yıldız Teknik Üniversitesi, İstanbul, 2013).

Ünsal Başak, “Kıbrıs'ın Doğu Akdeniz'de Türkiye Açısından Stratejik Önemi” (Yüksek Lisans Tezi, Mersin Üniversitesi, Mersin, 2006).

Yiğit Uçak, "The Changing Security Perceptions of the United States and the European Union in the Mediterranean Region" (Yüksek Lisans Tezi, Hacettepe Üniversitesi, Ankara, 2008).

Z. Behçet Kurt, “Akdeniz Eylem Planı'nın Türk-Yunan iliş̧ilerine Etkisi” (Yüksek Lisans Tezi, İstanbul Üniversitesi, İstanbul, 2002).

Zeki Arda Savcı, "Euro-Mediterranean Partnership and the Intercultural Dialogue" (Yüksek Lisans Tezi, Orta Doğu Teknik Üniversitesi, Ankara, 2006).

Zeynep Asu Talu, "Saving the Mediterranean: Med Plan and International Cooperation" (Yüksek Lisans Tezi, İhsan Doğramacı Bilkent Üniversitesi, Ankara, 1995).

Zeynep Kaleli, “The Evolution of European Union's Mediterranean Policy” (Yüksek Lisans Tezi, Marmara Üniversitesi, İstanbul, 2011). 